\begin{tabular}{|cc|c|}
\hline ISSN (Online): 2367-6957 & ISSN (Print): 2367-6361 \\
Izvestiya Journal of Varna University of Economics 3 (2020) \\
J Z V E S T I Y A
\end{tabular}

\title{
CIRCULAR ECONOMY: INTERNATIONAL POLICIES AND PRACTICES
}

\section{Virginia ZHELYAZKOVA ${ }^{1}$}

${ }^{1}$ VUZF, Sofia, Bulgaria. E-mail: vzhelyazkova@vuzf.bg

JEL: F0

Key words:

circular economy, governmental policies,

linear economic model.

\begin{abstract}
In the past years the importance of the topics related to circular economy has gained momentum. This is understandable given the accelerating climate change, pollution and the numerous environmental and economic challenges that are arising as fallout of them.

The aim of the current paper is to outline the key features of the policies of the countries leading in the efforts towards shifting from a linear to circular economic model - Japan, China and the European Union. Reviewing the main characteristics of their policies and efforts could bring a lot of light into the main crux of the question related to circular change - how it can take place in practice and what is necessary for it to happen.
\end{abstract}

(C) 2020 University of Economics - Varna Izvestiya Journal of Varna University of Economics, 64 (3), p. 239 - 255.

DOI: 10.36997/IJUEV2020.64.3.239

\section{Introduction}

"Circular economy" is a new term for a millennial-old concept. Historically, due to a number of circumstances mankind has followed mainly a circular economic model in which raw materials were used to create goods, and after the end of the useful life of these goods they were used to create new ones. The lack of technologies for processing raw materials as we know them today has necessitated this type of economic behavior. Scientific and technological progress leads to new opportunities 
to create a variety of goods at affordable prices, which gradually leads to an expansion of consumption. As a result of these processes, the linear economic model slowly began to emerge. It is characterized by the disposal of goods in landfills after the end of their useful life. Thus over time a number of environmental issues arise together with the need to rethink the way the economy functions. This is the reason for governments around the world to seek opportunities and ways to manage the negative effects of the linear model and to gradually transform it into a linear one.The subject of the present study is some policies and practices in Japan, China and the European Union (EU) which are leaders in the efforts to transform the linear economic model. Each of them has adopted its own political line in the direction it has chosen. For the purpose of the analysis presented, qualitative methods have been used that allow for interpretation of data and information related to the research subject.

\section{Japan's efforts towards circular economy}

Historically Japan was the first country in the world to systematically apply the principles of circular economy in its development. The basis of the policy pursued in Japan are the so-called 3 Rs (Reduce, Reutilize, Recycle) - reduction, reuse and recycling. The roots of this policy should be traced to the geographical, geological and historical features of this country. Territorial scarcity, combined with lack of natural resources, has forced Japanese governments over time to look for ways to organize the economy and society so as to consume minimal resources.

The Japanese shocks of the 1970s had a particularly strong influence on the formation of such a policy by the Japanese governments. These episodes clearly showed the country that in order to be a leading economic power, it must find a way to reduce as far as possible its dependence on fuel imports. However, this could only happen by redefining the economic model and directing it to the optimal use of different types of resources (Todorov, 2018). Of course, such an endeavor would not be feasible without the necessary knowledge and level of awareness in Japanese society. Governments are systematically working to build a comprehensive culture in the country aimed at optimizing the use of resources at all levels. This does not prove to be very difficult as such a way of thinking has been ingrained in the Japanese way of thinking for centuries.

Ji, Zhang and Hao highlight three steps in the development of the circular economy in Japan (Xiujun Ji et al., 2012).

The first phase covers the 1970s and 1980s and represents a transformation of the state's policy towards conventional energy sources. Following the oil shocks, 


\section{Zhelyazkova.}

Circular Economy: International Policies and Practices

Japanese governments began to pursue a two-pronged policy. On the one hand, they aim to diversify the use of conventional energy sources, as the share of coal and gas in the country's energy mix increases at the expense of oil. On the other hand, active actions for energy efficiency are being launched at all levels of production. This is possible both due to energy saving measures and as a result of shifting industry from energy-intensive sectors such as metal production to high-tech sectors. In this way, the country is gradually making significant progress not only in terms of energy consumption, but also in terms of developing and using its relative advantages.

The second phase is characterized by the development of a strategy for the use of renewable energy sources (Todorov, 2017). In 1994 Japan drew up a plan for the exploitation of energy from alternative sources. For the purposes of the plan these sources are divided into categories according to the time required for their recovery. For example, solar, wind and hydro energy are recovered in a very short time, while biomass sources (forests, animal species, etc.) require a longer recovery period. The use of renewable sources is becoming a national priority and contributes to building a circular economy in the country.

The third phase is related to the formation of such public consciousness in Japan which will support the efforts of governments to achieve their goals. The Japanese state has been working hard in this direction over the years, so that through the educational system the perception of the need for the most efficient use of natural resources is achieved (Rangelova, 2014). One can say that at the moment (2020) in Japan there is practically no need for a public debate on whether the circular economy is an appropriate model of economic development.

As Ji, Zhang and Hao point out, the legal system in Japan is designed to support the functioning of the circular economy. Over the past 27 years since 1993, a number of laws have been passed that stimulate various aspects of circular economy. The first category is fundamental, the second - comprehensive and the third - specific.

In general, the legislative framework in Japan is built on three levels: the Framework Law of 2000 on the Establishment of a Circular Society, the Law on the Promotion of Resource Efficiency and the Law on Waste Management of the same year, together with some sectoral laws addressing specific aspects of circular economy (Études \& documents, 2014).

It is characteristic of the Japanese legislation that it is developed in detail according to the specifics of the particular economic sectors. This is necessary due to the need to take into account the characteristics of individual products in terms of the materials from which they are made, as well as their lifespan. As waste treatment is organized by sector, regular monitoring of related activities is of great importance. 
Another feature of the Japanese model is the continuous monitoring of the feasibility of the set goals for waste recycling by sector and type of products. This follow-up is carried out with the assistance of independent experts.

During the first stage in the development of the legislative framework for the transition to circular economy in Japan, in 1991 the Law on the Promotion of the Use of Recyclable Resources was adopted. This law operates in parallel with the Waste Management Act, adopted in 1970 and has since undergone numerous changes and additions. The Waste Management Act mainly deals with the stage of the product's life when it is obsolete and must be disposed of. In 2000, the Recycling Act was renamed "the Resource Efficiency Act" and was amended to add the topic of reducing the amount of waste and reusing it.

In fact, it was these two laws that became the basis for Japan's fundamental Law on the Establishment of a Circular Society. This law defines the principles of circular economy. These principles include the so-called hierarchy of waste, its cascading use and the specific responsibilities of the various parties in the process.

In order to implement the described requirements in the legislative framework, the Japanese governments initiate the preparation of plans which are supplemented by specific action programs in various areas. The first such plan was adopted in 2003. Interestingly, the progress of the policy thus undertaken by the Japanese governments on their own initiative has been discussed and evaluated at the G- 8 in 2004 and 2008.

It is important to note that to support the success of the policy of establishing circular economy, the Government of Japan uses a number of measures to act as incentives for individual groups of economic entities. Different types of competitions have been created for the representatives of the different economic sectors, as well as awards for the organizations that achieve the best results. In this way, through the transparency of the results of everyone's efforts, the public consciousness is stimulated and the activities in the field of circular economy gain momentum. Examples of such initiatives are the top runner programs, the e-Mark eco-label, and the Eco Town program which are discussed below.

The "top runner" program aims to increase energy efficiency. It covers 21 product categories such as cars, various everyday goods and more. Once the minimum energy consumption has been established for each of the individual product groups covered by the program, it becomes a target, a standard for all other products in the same group. They must reach this goal within a certain period of time. These standards are set by a specially established Committee for Energy Consumption Standards at the Ministry of Economy, Trade and Industry. 


\section{Zhelyazkova.}

Circular Economy: International Policies and Practices

The initiative to put labels, so-called eco-labels, on products showing how close they are to the energy standard for their class, although the placement of "e-Mark" is voluntary for companies, turns out to be widely used. Labeling contributes significantly to the achievement of energy efficiency goals in Japan, because it promotes the competitive element among individual companies. As Angelov (2018) rightly says, competition allows technological innovations to develop. Interestingly, the placement of labels and the achievement of energy saving targets per unit of product are very closely monitored by the Committee. In cases where the objectives are not achieved, it has the power to impose sanctions. At the same time, information on the products for which the highest level of energy efficiency has been achieved is published twice a year in a special catalog.

The next effective initiative aimed at realizing the circular economy is known as "Eco Town". It was implemented in the period 1997-2007 under the supervision and with the support of the two key ministries - the Ministry of Economy, Trade and Industry, on the one hand, and the Ministry of Environment, on the other. This initiative has two main objectives. The first is to create eco-industrial parks, i.e. places where it becomes possible the production cycle to be closed so that waste products from one production become a raw material for another, while minimizing waste. The second is within these parks to create the necessary conditions to revive some economic sectors, such as heavy industry, which will already function under the new conditions for treatment of waste products from the activities carried out by them. Currently there are over 60 such projects in Japan.

There are three types of eco-cities in the country. The first category is located in large urban agglomerations and in large cities. The second - on the islands. The third one is in areas that cover many secondary cities, for whose waste solutions are sought for centralization at the regional level of recycling activities.

The procedure for approving a project for obtaining the name "eco-city" is as follows: the municipality within which the construction of the eco-city is planned, together with the companies that wish to participate, prepare a plan in which they present their project. It argues the need for its implementation, its sustainability from an economic point of view, its profitability, what innovations are planned to be introduced and whether it will use the best existing technologies. In addition, the project must demonstrate a very important quality for the Japanese government - to be able to serve as an example of other similar initiatives, as this should be evident from the plan for its implementation. The plan is submitted for approval to the two ministries. If it is approved, the state provides funding, and in some cases local authorities support the project in the form of loans. 
The main source of funding for projects aimed at the realization of a circular economy is the Development Bank of Japan. This specific activity is part of the Japanese state policy to promote sustainable governance in general. The specific financing of the individual projects is done through private banks. As Angelov (2020) points out, in the 21 st century the role of banks has grown significantly, strengthening their influence as part of key business institutions. This is the reason why the role of banks is essential in the process of transition to circular economy.

Three levels of interest rates for loan beneficiaries have been set. The level at which funding will be received depends on the applicants' answers to 120 questions concerning various aspects of their activities that are relevant to the environment.

Essential for the achievement of the government's goals for expanding the scope of the circular economy is the active state policy, which, as it has already become clear, is expressed in a number of activities and most importantly - in the overall direction of the process. Through the Ministry of Environment and the Ministry of Economy, Trade and Industry, the state monitors compliance with the norms of energy efficiency set for individual groups of products and individual products, imposes sanctions for noncompliance and rewards those who excel in various ways, setting examples to others. In addition, as already mentioned, these two ministries review and approve the plans for eco-towns, which are provided to them by the individual municipalities together with the interested companies, and subsequently, upon approval, the Development Bank of Japan provides funding. In addition to these very important activities for the success of the policy, in 1994 the state prepared and introduced a special plan aimed at all supplies to the parliament, the government, its various agencies and all government institutions in general, to meet certain environmental conditions. This is a very powerful tool to encourage all suppliers for the huge state administration to move to new production standards. And not only this; with the introduction of such a plan the state gives an unambiguous signal to other economic entities in which direction they should orient their way of production and consumption, that the current (until the introduction of the plan) way of work becomes absolutely unacceptable for it, and that it will use any measures to achieve change at both the macro and microeconomic levels. Innovative solutions lead to higher efficiency and competitiveness and build a positive reputation of the company (Lazarova, 2018); thus this is a very strong rationale for all actions of the Japanese governments.

In addition to this plan, the Green Purchase Promotion Act came into force in 2000. Thanks to its active policy Japan stands out as a country that is ahead of the most active countries in this regard in Europe - Germany and Sweden (Études \& documents, 2014). 


\section{Zhelyazkova.}

Circular Economy: International Policies and Practices

Another important direction in the policy of the Japanese state is the introduction of standards for the quality of recycled products, as it turns out that their lack is a serious obstacle to market realization. Local authorities in Japan play a key role in this important step, as they actively inform the central authorities about this problem and demand a solution so that they can purchase recycled products. Thus, within the framework of Japanese industry standards, those for recycled products have been created. Inclusion in these norms is a kind of guarantee for consumers for the presence of certain qualities of the products.

Progress in establishing circular society is being monitored strictly and continuously. According to a report back from 2010, when considering the results of the measures taken under the foreground, Japan had achieved very high results. For example, in the packaging sector, almost $100 \%$ recycling of materials has been achieved, with the exception of cardboard and glass packaging. In the sector of household appliances $85 \%$ recycling is achieved, and in the segment of construction waste for some materials such as concrete and wood $95 \%$ recycling is achieved, in the case of batteries - between $50 \%$ and $80 \%$ in the individual categories.

It can be summarized that Japan is a pioneer in the efforts to establish a circular economic model. Long before the idea of a circular economy was theorized in detail and gained social significance globally, it had been embedded in the very foundation of the state philosophy of economic model of this country. Of course, the roots of this philosophy should be sought in the historical past of Japan, as well as in its geographical features. Awareness of the need to ensure optimal efficiency of all economic processes is part of Japanese culture. It is to this culture and public consciousness that the success of state policy in the realization of a circular economy should be attributed. Japan is an example of how public institutions can play a leading role in the economic development (Dobreva, J. 2019) and how high awareness at individual level leads to improved efficiency and efficacy of collective action (Dimitrov, 2019).

\section{The policy of China for transofrimng the linear economic model}

China is the second Asian country to demonstrate an active policy towards circular economy. This country is characterized by high economic growth over the past few decades. Growth means the growing creation of goods of all kinds, and this in turn is linked to both the extensive extraction and processing of resources and the increasing consumption and therefore disposal of waste.

Gradually, in the 1990s, the need to organize recycling activities and minimize waste in general became clear at the highest governmental level in China. In 1999, the 
establishment of a special State Administration for Environmental Protection with the rank of a ministry was announced, which subsequently grew into the current Ministry of Environmental Protection in 2008. Since the beginning of 2000, the Chinese president has constantly proclaimed that circular economy is a priority of the state, and has insisted on working in this direction at all levels. The adopted policy was formalized in the Eleventh Five-Year Development Plan adopted in 2006, and the circular economy was declared a priority of the Chinese state.

As a result, in the same year intensive work began on drafting a law on the promotion of circular economy. This law was adopted in 2008 and came into force in the following year, 2009. The provisions in it are largely based on the Japanese and German experience. Special attention is paid to the support for the construction of industrial symbioses, eco-industrial parks and clean technologies. The field of action of this law is mainly waste, but it also extends to the use of resources - various raw materials, energy sources, water, soil and more.

Prior to the creation of this law there were several laws in China that dealt with the problems of circular economy by individual economic sectors. Six laws can be distinguished in this direction:

- Law on the Promotion of Clean Production (2003) and the methods for its auditing (2004);

- Law on the Prevention and Control of Environmental Pollution with Solid Waste (1995, amended in 2004);

- Energy Conservation (Good Governance) Act (1997);

- Law on Environmental Impact Studies (2003);

- Renewable Energy Act (2005).

In fact, all these laws are practically integrated into the Circular Economy Promotion Act, and the principles enshrined in them are included in it. The existence of sectoral laws dating back to the second half of the 1990s and the first years after 2000 testifies to the active search for mechanisms to support the efficient management of all types of resources in the Chinese economy. This is entirely understandable, given the ambitions of the Chinese governments to establish the country as a leading world economic power, which today could not be achieved without taking into account the problems of resource consumption and waste treatment.

Economic growth, so characteristic of the Chinese economy for decades, is unthinkable without the accumulation of huge amounts of waste, so the topic of circular economy naturally emerges as a leading one for the Chinese state. 


\section{Zhelyazkova.}

Circular Economy: International Policies and Practices

China's law to promote circular economy was followed by an important government decree on waste management from the production of various electrical and electronic products. It came into force in 2011.

The Law on the Promotion of the Circular Economy in China provides a general framework for action in this direction and is aimed at all economic entities: the state, local governments, companies, consumers. It outlines the specific measures to be applied by these economic entities, as well as sanctions for non-compliance. The measures to be implemented by local authorities are included in their action plans at regional level, which are subsequently summarized at national level. In this way, through law, the Chinese central government seeks to enforce the rules of action for all entities throughout the Chinese state, assigning them specific obligations within the process. Sanctions provided for non-compliance with this law include, as a last resort, the closure of businesses that use prohibited equipment, certain toxic substances, electrical equipment that does not meet Chinese standards, and more.

An important aspect of the application of this law at the local level in China is the obligation of local authorities to set up special teams to work in the direction towards circular economy. In addition, they are obliged to draw up detailed plans for the development of circular economy within the territories entrusted to them, setting out specific objectives in this direction, actions that will help to achieve them, as well as indicators showing the progress of efforts.

It is noteworthy that the subject of the Circular Economy Promotion Act in China has mainly the following aspects: on the one hand, the achievement of reduced use of certain resources, including through the application of clean technologies and renewable energy sources, and on the other - the opportunities for repeated use of certain raw materials in various projects in the field of industrial ecology and symbiosis, the latter relating primarily to heavy industry. Issues related to extending the life of products and improving their functionality (product design) are not subject to this law.

The provisions of the Circular Economy Promotion Act have been further developed in the twelfth five-year plan, which covers the period 2011-2015. In this plan some important aspects of the circular economy are highlighted, such as increasing energy efficiency, which includes electricity generation of hot air in cement plants, the use of methane, which is released during the operation of some coal mines, etc. In addition, the plan emphasizes the need to provide recycling conditions in the textile sector and also addresses the problems with the use of water used for industrial purposes. The Ministry of Trade sets a specific goal - to achieve $70 \%$ collection of recyclable resources so that their reuse (or reuse) can be made possible. 
Another important point in the twelfth plan is the emphasis on the development of eco-technologies that use minimal amounts of carbon dioxide, such as nuclear power and hybrid and electric cars.

According to a World Bank study on the circular economy in China, there are several types of obstacles to its deployment at a larger scale and to its faster implementation. Among them is the lack of specific statistics on the progress of companies working in this field, the lack of financial and fiscal indicators ans the insufficient knowledge among the administration in the provinces, which is relied on to play a key role in implementing government plans.

Despite the real and diverse difficulties facing the development of circular economy in China, the strong commitment of the state's efforts in this direction is impressive. In China, a comprehensive legal framework for circular economy has been developed and is in place, which defines both specific incentives and sanctions for individual economic operators and thus supports micro-level efforts. Legislative progress in China is probably also due to the territorial proximity to Japan, which has historically implemented various circular economy policies for the longest time, and whose experience is undoubtedly of great practical value to all other countries in the world.

\section{EU policy on circular economy}

Resource efficiency is also a priority for EU Member States. It is enshrined in the 2020 Strategy and in the Roadmap for a Resource-Efficient Europe adopted in 2011. This document sets out the specific actions that each Member State must take to achieve the overall goal. As defined in the 7th Environment Action Program, this goal states: the EU should "become a resource-efficient, green and competitive low-carbon economy ". Dimitrova (2019) notes that EU has taken specific financial measures for shouldering together the risks when investing in eco-innovations, environment protection and innovative technology.

To date no specific targets have been set in the EU for either resource use or efficiency. Germany makes an exception, with clear goals. At the national level, the development of programs and strategies for efficient use of resources is observed and in these documents, as a rule, the aim is naturally to address the problems of the specific economy. Initially, these problems covered energy consumption and waste recycling, but over time they gradually spread to other areas. Such are, for example, environmental pollution, the need to ensure security of supply of key raw materials, which are depleted over time, trends in rising energy and raw material prices, climate change and their impact on ecosystems, and more. 
V. Zhelyazkova.

Circular Economy: International Policies and Practices

As a result of the already existing individual policies and initiatives in some of the countries, at the end of December 2015, with a decision of the European Commission, the European Union announced as its priority the gradual transition from a linear to a circular model of the economy (Vazov, 2019). Since then, work has gradually begun to build a comprehensive concept of how this transition will take place, and the analyses and documentation have been formed into a special package. The main emphasis is placed on the legislation in the field of waste treatment, as it is their improper accumulation and closure within landfills that leads to a number of negative consequences for both the economy and the environment. The analyses that are carried out show that the economic benefits of changing the model will be significant. In addition to measures aimed at waste management, the Circular Economy Action Plan created for this purpose covers the entire production cycle from the creation of individual products to the ways of their processing. Specific objectives in this direction are outlined in the annex to the Action Plan.

Since waste management, as already mentioned, plays a key role in the transition to circular economy, it is important to note the new goals that the EU is setting in this area. First of all, by 2030 it is planned to recycle $75 \%$ of packaging waste and $65 \%$ of municipal waste. Secondly, it is envisaged that a maximum of $10 \%$ of the waste generated by municipalities will be disposed of in landfills. A ban on the operation of landfills for separate waste disposal is also introduced. In addition to these measures, various economic incentives are introduced to close landfills, specific measures to stimulate industrial symbiosis (the use of waste from one industry as a raw material for another), to support various recycling schemes, etc.

The implementation of the plan for the transition from linear to circular economy requires concentrated efforts in all areas of economic life. As Dimitrov (2014) notes, it is necessary and particularly essential for financial institutions as key players in the transition, to adopt the principles of good corporate governance. A document of the European Bureau of Ecology from March 2015 to the European Commission presents a concentrated analysis of the necessary measures to be taken in the EU.

The European Bureau has identified four main areas for action:

- durability of the products and the possibilities for their repair;

- stimulating demand;

- improving the product design;

- waste treatment through new approaches.

In the first area - increasing the durability of products and expanding the possibilities for their repair - a number of concrete actions are needed. For example, 
even when the products are in the design phase, consideration should be given to how they are designed to extend their useful life. This requires a lot of analysis and experimentation. Extending the life of products has a number of other consequences. If a product is to be used for a long time, it must be designed in such a way as to provide opportunities for its relatively easy repair. In order for this to happen, it is necessary to provide and produce the required number of spare parts. There must also be organizations that are ready to carry out the necessary repairs. This includes, in addition to having the necessary spare parts in sufficient quantity, also a workforce with the appropriate qualifications.Therefore, the educational system must also be actively involved in efforts to provide a basis for the development of circular economy. Educating specialists who have knowledge in the field of repair of various products is vital.

Another no less important issue is related to product design. If a product is to be used for a long time, it must not only be strong and resistant to damage (Vazov, 2018). The design should be emotionally durable, i.e. not aging quickly, in order to satisfy that part of the needs of the economic subjects which is related to the intangible benefit, i.e. with the pleasure of owning a product. Therefore, it is necessary to think about the development of such designs of individual goods that are durable to consumer desires. Here a very important role falls, on the one hand, on the educational system, on the other - on the media. These are the two systems that have the leverage to have the strongest impact on consumer habits, values, desires and therefore needs. The educational system (Vazov, 2019) should focus its efforts on educating young people in a culture that values circular economy in all its manifestations. Which means giving preference to durable objects, based on the understanding that using an object for a long time instead of throwing it away and replacing it with another one, without a real need, leads to negative consequences not only for the environment (contributes to increase in waste), but also for the personal economic well-being of the owner of the item. However, this means a major transformation in consumer thinking in Europe, characterized by a preference for continuous consumption and demand for new and new products. This way of thinking in Europe (and not only) is cultivated with the important help of the media, which receive funds for adcertisement from the producers and distributors of the goods themselves. Therefore, manufacturers and distributors must have a strong economic incentive to change their own behavior in the market.

It is the creation of a comprehensive system of measures aimed at this area that is key to changing the public consciousness - directing it from consumerism to rationality, without which the success of any major political change is not possible. 


\section{Zhelyazkova.}

Circular Economy: International Policies and Practices

In this regard, the Bureau's recommendations are aimed at creating two types of incentives. On the one hand, in order to encourage the companies that carry out and will carry out repair works, the tax burden for them should be reduced. This will create meaningful economic incentives that will be passed down the value chain of the services they offer. When the repair services of individual products are economically available and affordable, then relatively more consumers would prefer to give the items they use for repair than to spend money on new ones.

On the other hand, the tax burden on resource-intensive production sectors should be increased. This will lead to higher final prices of products in these sectors, and so when these prices are compared with the cost of repairing already acquired products, consumers will resort to buying new products only as a last resort.

There are many other aspects to using the products for a relatively long time. For example, consideration should be given to extending production guarantees, which will, of course, be different for different products. In addition, manufacturers need to be required to provide complete information on how products can be repaired, as well as spare parts to be available on the market for a long period (eg. 10 years) after the specific product has been put into service.

The next area of action in the EU for the transition to circular economy is related to stimulating demand for all types of services and related products (spare parts, spare software codes, etc.) related to maintaining a longer product life. To this end it is necessary to launch a broad public campaign to inform the people, as mentioned above, about the benefits of long-term use of individual products, as well as the use of individual elements or products made from recycled materials. When it comes to the individual consumer - a household or a small business - the choice is made on an individual level. However, the big consumers of various products are the powerful enterprises, the corporations with a large number of employees, the state and municipal administrations. It is very important to have specific conditions for selecting suppliers for the needs of such organizations according to strictly defined criteria, giving preference to companies that use durable products, work with environmentally friendly raw materials and/or recycled materials, or ensure the recycling of waste from the relevant activity.

Demand for the above group of goods and services can be stimulated indirectly through the wider deployment of various schemes, which involve the shared consumption of certain services and products or the use of leasing schemes. Shared consumption is one of the three modern trends that have changed the world in recent years, which aims to, as Andonov says (2014, p. 13), "maximizing the use of the planet's resources through shared consumption of products by more consumers." In 
shared consumption the maintenance costs of an item are distributed between the users, and in leasing schemes, the use of the products is again based on the use of the products, not on their purchase.

In order to facilitate the activities related to the repair of individual products, it is necessary to oblige manufacturers to provide detailed information on the materials of which they are composed, the presence of hazardous substances in them, methods of repair, life expectancy of these products, all their functionalities, etc. This can be done by introducing a passport for each product, which describes its most significant features. If important information is missing, the repair of the products will become impossible and the consumers will start to return to the well-known linear pattern of behavior.

Improving product design is the next key area that needs to be worked on systematically in order to make the transition to circular economy.

By "improvement" in this case we mean several specific things that partially summarize some of the considerations presented so far.

First of all, the products must be designed from the very beginning to last for a long time. As already mentioned, extending the life of products is key to reducing waste.

Secondly, the design must allow for the products to be repaired. Each product must be created from separate elements so that, if one of them ceases to function properly, it is be able to be replaced by another.

Third, it is important that the design allows for upgrades. As the products will have a long life and over time there will be improvements in their functionality, it will be extremely important that they can be upgraded, and for this purpose only individual elements will be replaced, while the basis of the products will be preserved.

Fourth, the design must allow for modernization. At present, due to the low cost of a number of goods, especially those for everyday use, it is much easier for consumers to dispose of them and buy new ones in their place than to look for ways to repair them; also, as soon as a new model of goods appears, to replace the old one with it. Therefore, it is very important that the individual products are constructed in such a way as to allow their moral depreciation to be compensated by renewing their external characteristics.

The next area of targeted efforts to establish circular economy in the EU is to treat waste through new approaches so that it is reduced at the expense of two things extending the life of products and recycling discarded materials and goods.

Organizing proper waste treatment is a key activity in the efforts to achieve circular economy. It could not be successful, if it were not based on various forms of economic incentives and sanctions to push individual economic actors in the desired 


\section{Zhelyazkova.}

Circular Economy: International Policies and Practices

direction. Economic measures in this direction could be, for example, higher taxes on producers of goods that are not recyclable (or at least not with current technologies) and that contain ingredients harmful to human health and the environment, and, on the other hand, tax preferences for manufacturers of recyclable products.

In order for the management of the various processes contributing to circular economy to be successful, it is very important that they are measured. There are a number of models, including modelling sustainable development (Dobreva, 2019), that provide answers to questions related to measuring the impact of decisions towards model change.

\section{Conclusion}

Despite the declared desire to change the economic model, the efforts of individual countries, even within the EU, remain fragmented. In some countries ouside Europe, such as Japan and China, circular economy can be said to be at the center of economic life. Comprehensive legislative frameworks have been established, which define the rights and obligations of the individual economic entities. A number of specific incentives and sanctions have been created for the individual actions taken. In the EU such detailed legislation is not a fact yet. Individual countries within its borders pursue their own national policies, have their own priorities and principles.

For change to take place, all countries in the world need to follow a common management philosophy. This is due to the fact that the modern globalized world is open and countries consume many goods that are not produced on their territory, so it is very difficult to pursue an effective policy aimed at circular economy individually.

\section{End Notes}

1. Act on Promotion of Procurement of Eco-friendly Goods and Services by the State and Other Entities.Available at: http://www.env.go.jp/en/laws/policy/green/1.pdf

2. The European environment - state and outlook 2015 / Cross-country comparisons / Resource efficiency - material resource efficiency and productivity. Briefing Published 18 Feb 2015.Available at:: http://www.eea.europa.eu/soer2015/countries-comparison/resource-efficiency\#tab-related-interactive-charts.

3. Decision no 1386/2013/EU of the European Parliament and of the Council of 20 November 2013 on a General Union Environment Action Programme to 2020 'Living well, within the limits of our planet.', Official Journal of the European Union, 28.12.2013, L354/171. 


\section{References}

1. Todorov, Kr. (2018) Operativnaiproizvodstvenastrategiazabiznesa. Sv. Gr. Bogoslov Publishing House, Sofia, ISBN: 9789548590471.

2. Xiujun Ji,Yongqing Zhang, LuyingHao. (2012) Analyses of Japanese Circular Economy Mode And its inspiration significance for China. Advances in Asian Social Science (AASS) 725, Vol. 3, No. 4, ISSN 2167-6429, p. 726.

3. Dobreva, J. (2019) Modelling Sustainable Development of the Economy. St. gr. Bogoslov publishing House, Sofia, ISBN978-954-8590-59-4.

4. Todorov, Kr. (2017) Teorianastrategicheskotoupravlenie. Sv. Gr. Bogoslov, Sofia,ISBN 9789548590440.

5. Rangelova, R. (2014) Ekologichnataetikanazeleniarastej. Sbornikdokladiot X konferenciaEkologichnaetika, priroda I ustoichivorazvitiena Bulgaria, Institutzaikonomicheskiizsledvania.

6. Comparaison internationale des politiques publiques en matière d'économie circulaire. (2014)Études \& documents, Commissariat Général au Développement Durablen ${ }^{\circ}$ 101, Janvier 2014, p. 11.

7. Angelov, R. (2018) Slivaniataipoglashtaniata v bankovia sector: teoretichnipodhodi I metodologichniaspekti v kontekstanabalgarskatapraktika, Chetirinadesetamejdunarodnanauchnakonferenceianamladiteucheninatema:

Ikonomikatana Bulgaria i ES v digitalniasviat, Sofia, UNSS,ISBN 978-954-8590-684.

8. Angelov, R. (2020) Slivaniataikonkurentnatasreda v bankovia sector. Teoriaipraktikanakontrola. Sv. Gr. Bogoslov, ISBN 978-954-8590-78-5

9. www.env.go.jp/en/laws/policy/green/1.pdf

10. Xie, Jian; Pinter, Laszlo; Wang, Xuejun. (2009) Developing a Circular Economy in China: Highlights and Recommendations. Banquemondiale, http:// documents.banquemondiale.org/curated/fr/2009/06/10818505/developing-circulareconomy-china-highlights-recommendations, Available on 7.05.2016.

11. Decision no 1386/2013/EU of the European Parliament and of the Council of 20 November 2013 on a General Union Environment Action Programme to 2020 'Living well, within the limits of our planet.', Official Journal of the European Union, 28.12.2013, L354/171.

12. The European environment - state and outlook 2015/Cross-country comparisons/Resource efficiency - material resource efficiency and productivity. Briefing Published 18 Feb 2015, Available on: http://www.eea.europa.eu/soer2015/countries-comparison/resource-efficiency\#tab-related-interactive-charts 
13. Circular Economy Strategy. Closing the loop - An EU action plan for the Circular Economy. Available at: http://ec.europa.eu/environment/circulareconomy/index_en.htm, retrieved on 19 August 2016.

14. Dimitrov, St. (2014) Capital Pension Funds: the changing role in South and Eastern European Countries. Economic Alternatives, University of National and World Economy, Sofia, Issue 4, 2014, p. 110 - 119, ISSN 1312-7462

15. Circular Economy Package 2.0. Some Ideas to Complete the Circle. March 2015. European Environmental Bureau. Available on: http://www.eeb.org/ index.cfm?LinkServID=1E2E1B48-5056-B741-DB594FD34CE970E9, 4.05.2016.

16. Andonov, St. (2014)Marketingovopozicionirance. Iztok-Zapad, Sofia.

17. Resource productivitiystatistics. Eurostat. March 2016. Available on: $\mathrm{http}: / /$ ec.europa.eu/eurostat/statistics-

explained/index.php/Resource_productivity_statistics\#DMC_and_GDP_growth_rates in_EU-28_and_Member_States_between_2000_and_2014_and_decoupling_issues.

18. The European environment - state and outlook 2015/Cross-country comparisons/Resource efficiency - material resource efficiency and productivity. Briefing Published 18 Feb 2015, Available on: http://www.eea.europa.eu/soer2015/countries-comparison/resource-efficiency\#tab-related-interactive-charts

19. Cross-country comparisons/Resource efficiency - material resource efficiency and productivity. Briefing Published 18 Feb 2015, Available on: http://www.eea.europa.eu/soer-2015/countries-comparison/resource-efficiency\#tabrelated-interactive-charts

20. Dobreva, J. (2019) Institutions and economic Development, St. Gr. Bogoslov Publishing House, Sofia, ISBN 978-954-8590-57-0.

21. Dimitrov, Y. (2019) The Syndrome of the Good Soldier and hIs Intelligent Emotions. St. Gr. Bogoslov Publishing House, Sofia, ISBN 978-954-8590-58-7.

22. Gallucci, T., Lagioia, G., Dimitrova, V. et al. (2019) Theory and practice of circular economy, Direct Services, Sofia. 